\title{
Experimental study on thermal conductivity of teak wood dust reinforced epoxy composite using Lee's apparatus method
}

\author{
Ramesh Chandra Mohapatra ${ }^{1, *}$, Antaryami Mishra ${ }^{2}$, Bibhuti Bhushan Choudhury ${ }^{2}$ \\ ${ }^{1}$ Mechanical Engineering Department, Government College of Engineering, Keonjhar, India \\ ${ }^{2}$ Mechanical Engineering Departmet, Indira Gandhi Institute of Technology, Sarang, India \\ Email address: \\ rameshmohapatra75@gmail.com (R. C. Mohapatra)
}

\section{To cite this article:}

Ramesh Chandra Mohapatra, Antaryami Mishra, Bibhuti Bhushan Choudhury. Experimental Study on Thermal Conductivity of Teak Wood Dust Reinforced Epoxy Composite Using Lee's Apparatus Method. International Journal of Mechanical Engineering and Applications.

Vol. 2, No. 6, 2014, pp. 98-103. doi: 10.11648/j.ijmea.20140206.13

\begin{abstract}
In the present work, the effective thermal conductivity of teak wood dust (TWD) filled epoxy composites at different volume fractions $(6.5,11.3,26.8$ and 35.9\%) have been determined experimentally by using Lee's Apparatus. Composites of teak wood dust particles of $150 \mu, 200 \mu$ and $250 \mu$ sizes with varying volume fractions $(6.5,11.3,26.8$ and $35.9 \%$ ) have been developed by hand lay up technique. From the tests it is observed that for each size of TWD, the thermal conductivity values of composites decreases with increase of filler content which indicates that the TWD reinforced epoxy composites have good insulation properties. It has also been found that the composite with $150 \mu$ particle size of teak wood dust at same volume fractions exhibited lowest thermal conductivity compared to composites with $200 \mu$ and $250 \mu$ of teak wood dust. Therefore the composite with particle size $150 \mu$ at $35.9 \%$ volume fraction teak wood dust may be more suitable for insulation applications. Experimental results (TWD,150 $\mu$ ) are also compared with the theoretical models (such as Rule of Mixture model, Russel model, Maxwell model Baschirow \& Selenew model ) and found that the errors associated with all the above four models with respect to experimental ones lie in the range of 20.14 to $84 \%, 74$ to111.84\%, 79.13 to $115.79 \%$ and 60.13 to $102 \%$ respectively.
\end{abstract}

Keywords: Lee's Apparatus, Epoxy, Teak Wood Dust Composite, Thermal Conductivity, Error Analysis

\section{Introduction}

Now a days the synthetic fibre composites are replaced by environment friendly materials such as natural fibre like wood,banana, cotton, coir, sisal, jute etc. because natural fibre composites posses better electrical resistance, good thermal and acoustic insulating properties and higher resistance to fracture. In addition, natural fibres have many advantages over synthetic fibres, for example low weight, low density, low cost, acceptable specific properties, renewable and have relatively high strength and stiffness and cause no skin irritations. A better understanding of their physical properties, mechanical and thermal behaviors will enable engineers to produce optimum design for a structure. The thermal conductivity of a composite depends upon the thermal conductive nature of the fibre, matrix properties as well as their volume fractions, sizes, shapes, thickness, orientations and perfect bonding between the constituents. In recent days natural fibre composite materials are widely used in building components to reduce heat transfer in air conditioned buildings in order to decrease energy consumption, in automotives such as car door panels, car roofs, covers etc. These materials are also familiar in interior applications such as furniture and packaging for electrical appliances. The present work relates to investigations on thermal conductivity of epoxy matrix composites filled with teak wood dust due to the following reasons (a) most of the investigations are aimed at enhancing the thermal conductivity of the polymer rather than attempting to improve its insulation capability. (b) although a large number of particulates have been used as fillers in the past, there is no report available on bio-based materials like any kind of wood dust being used for composite making. (c) investigations on thermal conductivity of particulate filled composites are rare. (d) the understanding of the relationship between the effective thermal conductivity of a composite 
material and the micro-structural properties (volume fractions, distribution of particles, aggregation of particles, properties of individual components, etc.) is far from satisfactory.

\section{Review of Literature}

Thermal conductivity is an important thermal property for selecting materials for building construction and other applications. Some studies have investigated the thermal conductivity of thermo plastic composites, but few have explored the thermal conductivity of natural fibre reinforced (wood based) composites. Russell [1] developed a model using the electrical analogy. He derived an equation for the thermal conductivity of the composite using a series parallel network. Maxwell [2] studied the effective thermal conductivity of heterogeneous materials and developed first theoretical model for two phase system. Baschirow and Selenew [3] developed a model to calculate thermal conductivities of the real media. Ten wolde et al. [4] reported thermal conductivity of composites in longitudinal direction to be $1.5-2.8$ times greater than to the transverse direction. Suleiman et al. [5] investigated the thermal conductivity of wood in both longitudinal and transverse directions in the temperature range of $20^{\circ} \mathrm{C}$ to $100^{\circ} \mathrm{C}$. Their results showed that thermal conductivity is about 1.5 times more in the longitudinal direction than in the transverse direction due to non-homogenous nature of wood. Alsina et al. [6] presented the thermal properties of jute-cotton; sisal-cotton and ramiecotton hybrid reinforced unsaturated polyester composites. The results showed that sisal-cotton hybrid polyester composites have the thermal conductivity $0.213-0.25 \mathrm{~W} / \mathrm{m}-{ }^{0} \mathrm{k}$, jute-cotton hybrid polyester composites have the thermal conductivity $0.10-0.237 \mathrm{~W} / \mathrm{m}-{ }^{0} \mathrm{k}$, and Ramie-cotton hybrid polyester composites have thermal conductivity 0.19$0.22 \mathrm{~W} / \mathrm{m}-0 \mathrm{k}$. Abdullah [7] presented theoretical and experimental investigations of composite material as thermal insulation consists of natural fibres (white feather, Jute, Egg shell and Black feather). The results showed that the Jute composite material gives good results as composite thermal insulation compared with other natural composite materials. Haddadi et al. [8] investigated the thermal behavior of hollow conductive particle filled in epoxy resin using 3-D finite element computation. The computational results showed an increase of the effective thermal conductivity with increasing wall thickness of the hollow particle. However, for a large contact resistance and/or for a high effective thermal conductivity, it was shown that the contact resistance has a dominant influence on the effective thermal conductivity of the composite. Prisco [9] investigated experimentally the thermal conductivity of wood flour (WF) filled high density polyethylene composite (Wood plastic composite, WPC). Experimental results showed that the WPC thermal conductivity decreases with the filler content and WF content. Mohapatra et al [10] determined the thermal conductivity of the palm fibre reinforced polyester composites at different volume fractions of the fibre experimentally by using Lee's apparatus. The experimental results showed that the thermal conductivity of the composite increases with increase in fibre percentage. Mohapatra et al [11] also investigated the thermal conductivity of composites of epoxy reinforced with pine wood dust (PWD) at different volume fractions experimentally by using Lee's apparatus. The experimental results show that the incorporation of pine wood dust results in reduction of thermal conductivity of epoxy resin and there by improves its thermal insulation capability.

\section{Thermal Conductivity Models}

Many theoretical and empirical models have been proposed to predict the effective thermal conductivity of two phase mixtures. Some of them are cited below.

Series Model (Rule of Mixture):

$$
\frac{1}{\mathrm{~K}_{\mathrm{c}}}=\frac{1-\varphi}{\mathrm{K}_{\mathrm{m}}}+\frac{\varphi}{\mathrm{K}_{\mathrm{f}}}
$$

Where c- composite, m- matrix, f-filler, $\Phi$ - volume fraction of filler and K-Thermal conductivity

Parallel model:

$$
\mathrm{K}_{\mathrm{c}}=(1-\phi) \mathrm{K}_{\mathrm{m}}+\phi \mathrm{K}_{\mathrm{f}}
$$

Where $K_{c}$ - Thermal conductivity of composite, $\mathrm{K}_{\mathrm{m}}$ Thermal conductivity of matrix, $\mathrm{K}_{\mathrm{f}^{-}}$Thermal conductivity of filler and $\Phi$ - is the volume fraction of the filler.

Maxwell model:

The derived equation is:

$$
K_{c}=K_{m}\left[\frac{K_{f}+2 K_{m}+2 \varphi\left(K_{f}-K_{m}\right)}{K_{f}+2 K_{m}-\varphi\left(K_{f}-K_{m}\right)}\right]
$$

Russel model:

$$
\mathrm{K}_{\mathrm{c}}=\mathrm{K}_{\mathrm{m}}\left[\frac{\phi^{\frac{2}{3}}+\frac{\mathrm{K}_{\mathrm{m}}}{\mathrm{K}_{\mathrm{f}}}\left(1-\phi^{\frac{2}{3}}\right)}{\phi^{\frac{2}{3}}-\phi+\frac{\mathrm{K}_{\mathrm{m}}}{\mathrm{K}_{\mathrm{f}}}\left(1+\phi-\phi^{\frac{2}{3}}\right)}\right]
$$

Baschirow and Selenew model:

$$
\mathrm{K}_{\mathrm{c}}=\mathrm{K}_{\mathrm{m}}\left[1-\frac{\mathrm{a}^{2} \pi}{4}+\frac{\mathrm{a} \cdot \pi \cdot \mathrm{p}}{2}\left\{1-\frac{\mathrm{p}}{\mathrm{a}} \ln \left(1+\frac{\mathrm{a}}{\mathrm{p}}\right)\right\}\right]
$$

Where

$$
\mathrm{p}=\frac{\mathrm{K}_{\mathrm{f}}}{\mathrm{K}_{\mathrm{m}}-\mathrm{K}_{\mathrm{f}}}, \quad \mathrm{a}=\left(\frac{6 \phi}{\pi}\right)^{\frac{1}{3}}
$$

\section{Experimental Details}

\subsection{Materials}

Teak wood dust collected from a local vendor. has been chosen as the reinforced material mostly for its light weight, low density $(0.8 \mathrm{~g} / \mathrm{cc})$ and low thermal conductivity 
$\left(0.085 \mathrm{~W} / \mathrm{m}^{0} \mathrm{~K}\right)$. Epoxy (LY 556 and the corresponding hardener HY 951 supplied by Hindustan Ciba Geigy Ltd, India) has been used as matrix material.

Table 1. Properties of Materials

\begin{tabular}{lll}
\hline \multirow{2}{*}{ Properties } & Material's value & \\
\cline { 2 - 3 } & Teak wood dust & Epoxy \\
\hline Density(g/cc) & 0.800 & 1.200 \\
Thermal conductivity(W/m-K) & 0.085 & 0.363 \\
Young's modulus of elasticity(Gpa) & 10.500 & 20.000 \\
Tensile strength(Mpa) & 95.000 & 75.000 \\
\hline
\end{tabular}

\subsection{Composite Preparation}

The low temperature curing epoxy resin and corresponding hardener were mixed in a ratio of 10:1 by weight as recommended. The composite samples have been prepared by using hand-lay-up technique to measure the thermal conductivity (using Lee's apparatus) of teak wood dust (with average size $150 \mu, 200 \mu$ and $250 \mu$ respectively) reinforced in epoxy resin. A mould of $110 \mathrm{~mm}$ diameter and $5 \mathrm{~mm}$ thickness was made from a stainless steel sheet (Fig.1). It was coated with wax and silicon spray was used as releasing agent for easy removal of the sample. The cast composite was cured under a load of about $50 \mathrm{~kg}$ for 24 hours before it was removed from the mould. Then this cast was post cured in air for another 24 hours. The specimens were prepared having dimension of $110 \mathrm{~mm}$ diameter with thickness of $5 \mathrm{~mm}$.

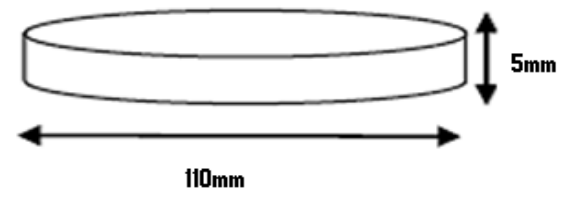

Fig. 1. Standard dimensions of specimen

\subsection{Experimental Set up}

The thermal conductivity test was carried out with Lee's disc apparatus as shown in Fig.2. The Nickel disc (N) is hung from the stand with the help of three strings. A heating chamber $(\mathrm{H})$ with facility of passage of steam in and out is created. Metallic disc (M) is placed on the top of a heating chamber $(\mathrm{H})$. Sample disc $(\mathrm{S})$ is placed in between metal disc and nickel disc. Two holes are made in the nickel disc $(\mathrm{N})$ and metallic disc (M) for the insertion of thermometers to measure the temperature.

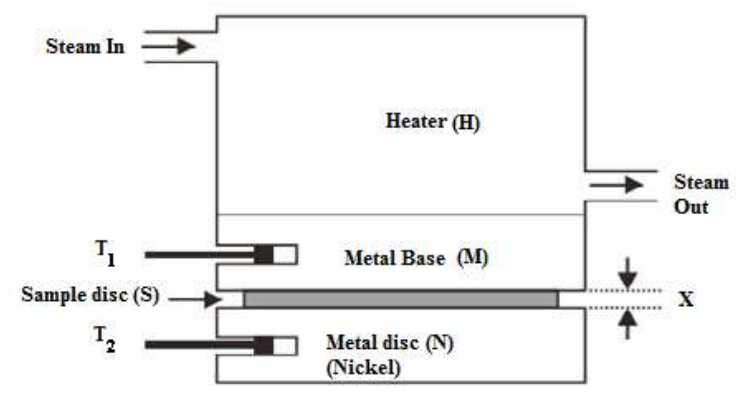

Fig. 2. Schematic diagram of Lee's disc Apparatus.

\subsection{Working Procedure}

Initially mass of the nickel disc $(\mathrm{N})$ was measured using a balance. Diameter of the specimen was found out using Vernier Caliper and the thickness was measured using a screw gauge. After this

- The heater $(\mathrm{H})$ was started by sending steam through the heating chamber. The temperatures $T_{1}$ and $T_{2}$ were recorded at a regular interval of 5 minutes till they reached the steady state.

- Then, the supply of steam was cut off and nickel disc (N) and specimen or sample disc (S) were removed. Heat was supplied to the nickel disc $(\mathrm{N})$ along with the sample(S) with the help of Bunsen burner so that nickel disc along with sample is heated to a temperature $10^{\circ} \mathrm{C}$ above the steady state temperature $\mathrm{T}_{2}$. After that the Bunsen burner was removed and allowed the nickel disc $(\mathrm{N})$ to cool. Temperatures were noted in every half a minute until the temperature falls about $10^{\circ} \mathrm{C}$ from steady state temperature $\mathrm{T}_{2}$.

- Variation of temperature of Nickel disc with time of cooling was plotted as shown in Fig. 3. A tangent is drawn at the steady state temperature $\mathrm{T}_{2}$. Thus the slope of this tangent gives the rate of cooling $\partial T / \partial t$ at steady state temperature $\mathrm{T}_{2}$.

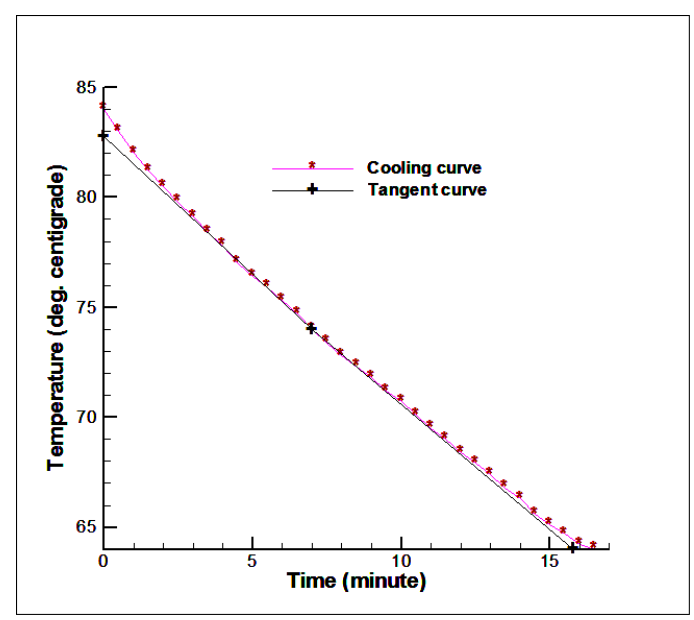

Fig. 3. Cooling rate of composite (Temperature-Time curve)

\section{Thermal Conductivity Measurement}

The rate of heat conducted through the specimen or sample is

$$
\mathrm{Q}=\mathrm{KA}\left(\mathrm{T}_{1}-\mathrm{T}_{2}\right) / \mathrm{L}
$$

Where, $\mathrm{L}$ is the thickness of the sample, $\mathrm{A}$ is the area of cross section of the sample, $\mathrm{K}$ is the thermal conductivity, $\mathrm{Q}$ is the rate of heat transfer and $\left(\mathrm{T}_{1}-\mathrm{T}_{2}\right)$ is the temperature difference.

The rate of heat lost by the nickel disc $(\mathrm{N})$ to the surrounding under steady state is

$$
\mathrm{Q}=\mathrm{mc}(\partial \mathrm{T} / \partial \mathrm{t})_{\mathrm{T}_{2}}
$$


Where, $\mathrm{m}$ is the mass of nickel disc $(\mathrm{N}), \mathrm{c}$ is the specific heat of the brass disc (B) and ( $\partial T / \partial t)$ is it's rate of cooling at $\mathrm{T}_{2}$

Comparing equations 6 and 7

$$
\mathrm{K}=\mathrm{mc}(\partial \mathrm{T} / \partial \mathrm{t})_{\mathrm{T}_{2}} / \mathrm{A}\left(\mathrm{T}_{1}-\mathrm{T}_{2}\right) / \mathrm{L}
$$

$(\partial T / \partial t)_{T_{2}}$ and $\left(T_{1}-T_{2}\right)$ is calculated using Lee's disc apparatus. Giving the input value of mass of nickel disc $(\mathrm{N})$, specific heat of the nickel disc, thickness of the sample and area of cross section of the of the sample, the thermal conductivity is calculated.

\section{Results and Discussion}

The thermal conductivity of the filler (TWD) and the epoxy resin have been evaluated by extrapolating the linear regression of the thermal conductivity values of the composite to $100 \%$ filler content and zero $\%$ filler content. It is found that the thermal conductivity of filler (TWD) and epoxy resin are $0.085 \mathrm{~W} / \mathrm{m}-{ }^{0} \mathrm{~K}$ and $0.363 \mathrm{~W} / \mathrm{m}-{ }^{0} \mathrm{~K}$ respectively. The behavior of the thermal conductivity values of different composites can now be explained using the thermal conductivity values of filler and epoxy resin. In this study, the thermal conductivity values of teak wood dust (TWD) reinforced with epoxy composites at different volume fractions of TWD is presented in Table 2. Figure 4 shows that for each size of TWD, the thermal conductivity of composite decreases with increase of filler contents which indicates that the TWD reinforced epoxy composites have good insulation properties. This is because the core of the filler is porous and air voids are created during preparation of composite. It has also been found that as the particle sizes of the TWD filler increases the thermal conductivity values with different filler content increases. In this Figure 4 the TWD filler with three different particle sizes $(150 \mu, 200 \mu$ and $250 \mu)$ are compared and found that the thermal conductivity values of $150 \mu$ (TWD filler) at same filler contents is least. From the above discussion it is concluded that choosing $150 \mu$ size is most advantageous one as it has best insulation properties on comparison to $200 \mu$ and $250 \mu$ particle sizes of TWD filler.

In this study, the effective thermal conductivity values of teak wood dust (TWD) at different volume fractions (i.e. $6.5 \%, 11.3 \%, 26.8 \%$ and $35.9 \%$ respectively) filled with epoxy composites is investigated experimentally. The obtained values are compared with four different theoretical thermal conductivity models as shown in Fig.5. From this figure, it is found that the experimental results along with all four theoretical thermal conductivity models are close to each other at low filler content. After that as the filler content increases the thermal conductivity values obtained from experiment as well as from theoretical models decreases accordingly. It has also been found that all four theoretical models shown in Fig.4 overestimate the values of thermal conductivity obtained from the experimental one. This may be due to some of the assumptions taken for models are not practical. Further in theoretical models orientation of the fillers was assumed to be perfect, but in actual practice, when liquid matrix is powered over the fillers some of the fillers may be misaligned. However at higher volume fractions of the TWD filler the experimental values of thermal conductivity are in agreement with the predicted values. On comparison, it has been found that the errors associated with all the above four models with respect to experimental one lie in the range of 20.14 to $84 \%, 74$ to $111.84 \%, 79.13$ to $115.79 \%$ and 60.13 to $102 \%$ respectively. The values of thermal conductivity and percentage of errors associated with each method for individual composite with two components i.e. teak wood dust (TWD) filler and epoxy are given in Table 3 and Table 4 respectively

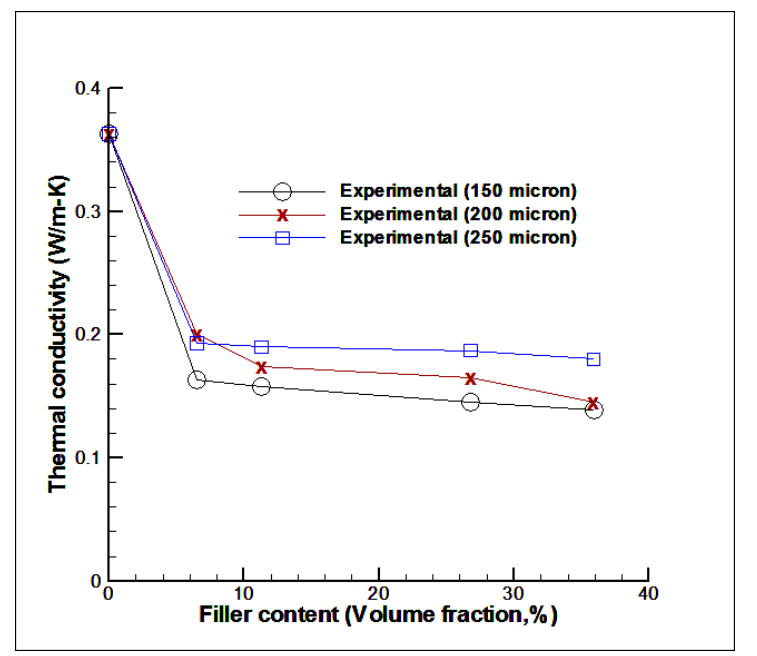

Fig. 4. Thermal conductivity of epoxy composites as a function of filler content (TWD)

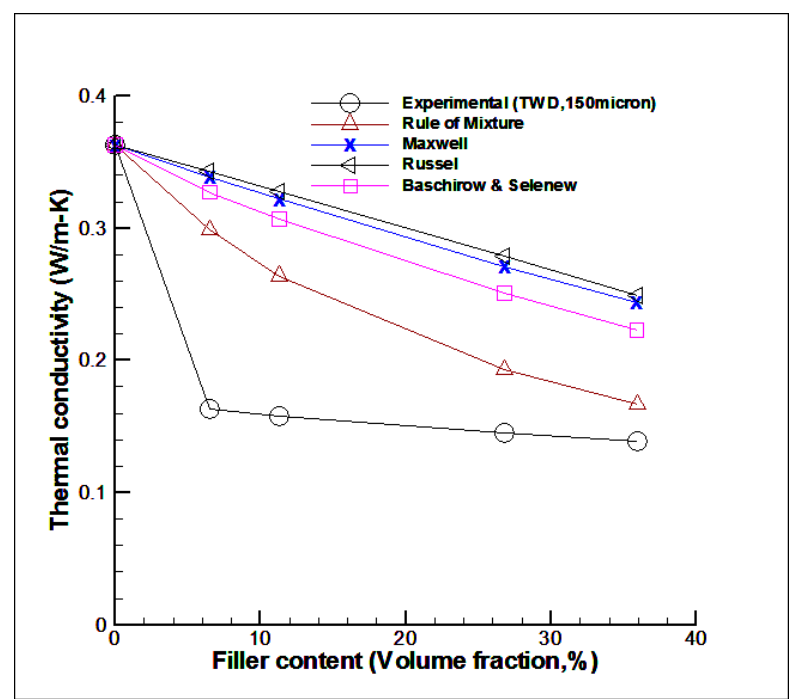

Fig. 5. Comparison of thermal conductivity of different methods with varying filler (TWD) content 
Table 2. Measured thermal conductivity values of composites of varied composition \& particle size of TWD

\begin{tabular}{lllll}
\hline \multirow{2}{*}{ Sample } & Particulate content (Volume & \multicolumn{3}{l}{ Thermal conductivity values of composites(W/m-K) } \\
\cline { 2 - 4 } & fraction, \%) & $\mathbf{1 5 0 m i c r o n}$ & 200micron & 250micron \\
\hline 1 & 6.5 & 0.163 & 0.201 & 0.193 \\
2 & 11.3 & 0.152 & 0.174 & 0.189 \\
3 & 26.8 & 0.145 & 0.165 & 0.187 \\
4 & 35.9 & 0.139 & 0.145 & 0.180 \\
\hline
\end{tabular}

Table 3. Thermal conductivity values of composites obtained from different methods

\begin{tabular}{lllllll}
\hline \multirow{2}{*}{ Sample } & \multirow{2}{*}{$\begin{array}{l}\text { Particulate content } \\
\text { (Vol.\%) }\end{array}$} & \multicolumn{2}{l}{ Effective thermal conductivities of composites (W/m-K) } & & \\
\cline { 3 - 7 } & Rule of mixture & Maxwell & Russel & Baschirow\&Selenew & Experimental \\
\hline 1 & 0 (Neat epoxy) & 0.363 & 0.363 & 0.363 & 0.363 & 0.363 \\
2 & 6.5 & 0.300 & 0.339 & 0.343 & 0.327 & 0.163 \\
3 & 11.3 & 0.264 & 0.322 & 0.328 & 0.307 & 0.152 \\
4 & 26.8 & 0.193 & 0.271 & 0.279 & 0.251 & 0.145 \\
5 & 35.9 & 0.167 & 0.243 & 0.249 & 0.223 & 0.139 \\
\hline
\end{tabular}

Table 4. Percentage errors with respect to the experimental value

\begin{tabular}{llllll}
\hline \multirow{2}{*}{ Sample } & \multirow{2}{*}{ Particulate content $($ Vol. $\%)$} & \multicolumn{4}{l}{ Percentage of errors with respect to the Experimental value } \\
\cline { 3 - 6 } & & Rule of mixture & Maxwell & Russel & Bashirow \& Selenew \\
\hline 1 & 0 (Neat epoxy) & 0 & 0 & 0 & 0 \\
2 & 6.5 & 84.00 & 108.00 & 110.43 & 100.61 \\
3 & 11.3 & 73.68 & 111.84 & 115.79 & 102.00 \\
4 & 26.8 & 33.10 & 86.90 & 92.41 & 73.10 \\
5 & 35.9 & 20.14 & 74.82 & 79.13 & 60.13 \\
\hline
\end{tabular}

\section{Conclusion}

Out of the results obtained it may be concluded that the teak wood dust as reinforcing material is an eco-friendly, nontoxic, low cost and easily available material as compared to synthetic fibres. Epoxy as a matrix material has been used in a wide variety of products such as adhesives, casting compounds, body solders and encapsulates. Good chemical resistance, excellent mechanical properties and modification versatility make epoxy attractive while it's inherent low viscosity and volatility as well as moderate cure temperature allow for production ease. The measured values of effective thermal conductivity are obtained for different volume fractions of teak wood dust fillers. Incorporation of teak wood dust results in reduction of thermal conductivity of composites there by improves its thermal insulation capability From the experiments it is observed that the composite with particle size $150 \mu$ at $35.9 \%$ volume fraction teak wood dust exhibited lowest thermal conductivity i.e $0.139 \mathrm{~W} / \mathrm{m}-\mathrm{K}$. Therefore the composite with particle size $150 \mu$ at $35.9 \%$ teak wood dust may be more suitable for insulation applications and coatings. The results of this study indicate that teak wood dust reinforced composites are light in weight, economical as it is easily available and posses a good thermal insulating properties. Hence the newly developed composite materials can be used for applications in automobile interior parts, electronic packages, ceiling roofs, building constructions, sports goods and furniture etc.

\section{References}

[1] Russell HW. Principles of heat flow in porous insulation, $J \mathrm{Am}$ Ceram Soc .18(1935), 1.

[2] Maxwell JC. "A Treaties on Electricity and Magnetism," $3^{\text {rd }}$ ed. New York,: Dover; (1954).

[3] Baschirow AB, Manukian AM. Thermal conductivities of polymers at various temperatures and pressures Mech. Polim (1974), 3, pp.564.

[4] TenWolde, A., McNatt, J.D., Krahn, L. "Thermal Properties of wood and wood panel products for use in buildings", Oak Ridge

NationalLaboratoryhttp://www.fpl.fs.fed.us/documnts/pdf198 8/tenwo88a.pdf.

[5] Suleiman B. M., Larfeldt J., Leckner B. and Gustavsson M.,"Thermal conductivity and diffusivity of wood," Wood Sci. Technol. Vol. 33 (6), 1999, pp. 465-473.

[6] Alsina, OLS, de Carvalho, LH, Ramos Filho, FG, d Almeida. JRM, "Thermal properties of hybrid lingo cellulosic fabric reinforced polyester matrix composites," Journal of Polymer Testing, Vol. 24, 2005, pp. 81-85.

[7] Abdullah Fadhel Abbas, "Theoretical and Experimental investigation of natural composite materials as thermal insulation," Al- Qadisiya Journal for engineering sciences, Vol. 4 (2), 2011. 
[8] Haddadi Manel, Agoudjil Boudjemaa, Boudenne A hollow particles,"bderrahim and Garnier Bertrand, "Analytical and numerical investigation on effective thermal conductivity of polymer composites filled with conductive hollow particles,'International Journl of Thermophysics,2013.

[9] Prisco Umberto, "Thermal conductivity of flat-pressed wood plastic composites at different temperatures and filler content," Science and engineering of composite materials, Vol. 0, Issue 0, 2013, pp. 1-8.
[10] Mohapatra Ramesh Chandra, Mishra Antaryami and Choudhury Bibhuti Bhushan, "Investigations on Thermal Conductivity of Palm Fibre Reinforced Polyester Composites," IOSR Journal of Mechanical and Civil Engineering (IOSRJMCE) Volume 11, Issue 1 Ver. I (Feb. 2014), PP 01-05.

[11] Mohapatra Ramesh Chandra, Mishra Antaryami and Choudhury Bibhuti Bhushan, "Measurement on Thermal Conductivity of Pine Wood Dust Filled Epoxy Composites" American journal of Mechanical Engineering, Vol. 2, Issue 4 (2014), pp 114-119. DOI:10.12691/ajme-2-4-3. 